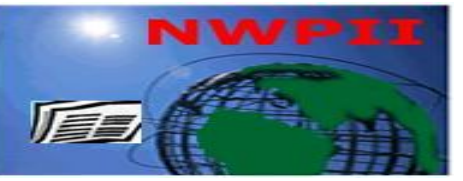

American Journal of Biomedical Sciences

ISSN: 1937-9080

nwpii.com/ajbms

\title{
Antibacterial and Anti-inflammatory Potential Bergenia ligulata
}

\section{Tehseen Sajad ${ }^{1}$, Afzal Zargar ${ }^{1 *}$, Tasleem Ahmad ${ }^{2}$, G N Bader ${ }^{2}$, Mohammad Naime ${ }^{2}$, Shakir Ali ${ }^{2}$}

${ }^{1}$ Department of Biochemistry, University of Kashmir, Hazratbal, Srinagar, Jammu and Kashmir, India

${ }^{2}$ Department of Biochemistry, Faculty of Science, Jamia Hamdard, Hamdard Nagar, New Delhi-110062, India

*Corresponding Author:

Dr. M Afzal Zargar,

Assosciate Professor, Department of Biochemistry, University of Kashmir

Hazratbal, Srinagar, Kashmir, J\&K

Cell: 9419016466

Email: zargarma@yahoo.co.in, zargarma@kashmiruniversity.ac.in

Received: 13 November 2009; | Revised: 8 March 2010; | Accepted: 6 May 2010

\begin{abstract}
Bergenia ligulata Wall., family Saxifragaceae, is an Indian folk medicine used for a variety of pharmacological effects. In this study, evidence is provided in animal model to demonstrate the role of aqueous as well as $50 \%$ ethanolic extract of B. ligulata in inflammation and as antibacterial agent. Oral administration of the extract at a dose level of $1 \mathrm{gm} / \mathrm{kg}$ bw showed anti-inflammatory and free radical scavenging activity as evaluated using pharmacological and biochemical parameters. The effect was studied on biochemical parameters reportedly perturbed in inflammation. While the extract treatment could alleviate the level of succinate dehydrogenase and xanthine oxidase, which increase in inflammation, the level of superoxide dismutase increased following the treatment with the extract as well as the diclofenac. Role of oxygen free radicals/peroxides was evaluated by measuring lipid peroxidation and glutathione. Treatment with the extract could significantly decrease the enhanced level of lipid peroxidation in inflammation, and increased the level of glutathione. Further, the antibacterial activity of various fractions was tested in vitro using cultures of Escherichia coli, Baccillus subtilis, and S. aureus, and the fractions were found to be antibacterial. The antifungal activity was also tested using the culture of Saccharomyces. However, the drug was ineffective in inhibiting fungal growth. Results provide evidence suggesting the anti-inflammatory as well as the antibacterial role of $B$. ligulata, thus implicating the plant extract in treatment against the bacterial infection and inflammation.
\end{abstract}

Keywords: Bergenia ligulata; anti-inflammatory; antibacterial.

\section{Introduction}

Bergenia ligulata Wall. (Syn. Saxifraga ligulata), family Saxifragaceae, is found in South and East Asia. In India, it grows at high altitudes in the Himalayas usually in rocky areas and in the Kashmir valley where it is popularly known as Paashaanbhed. The rhizomes of Paashaanbhed have been used for centuries in Indian System of Medicine [1] and the effects of the herb on kidney 
stone formation [2] and on influenza virus [3] have been validated. Chemical investigations have shown the presence of $\beta$-sitosterol, $\beta$-sitosterol-Dglucoside, bergenin [4] and paashaanolactone [5]. Bergenin and $\beta$-sitosterol are well known for pharmacological actions. In this study, the antiinflammatory, and antimicrobial activity of the crude plant extracts prepared from the rhizomes of $B$. ligulata is described. The role of free radicals that are important in inflammatory processes such as in the activation of NF- $\kappa \mathrm{B}$ (Ali and Mann, 2004), which induces the transcription of inflammatory cytokines and cyclooxygenase, is also investigated in this study in terms of biochemical parameters.

\section{Materials and methods}

\subsection{Animals}

Pathogen free adult male Wistar strain of rat (220-260 g) was used throughout the study. The animals were procured from the Central Animal House Facility of Jamia Hamdard, grouped randomly (six in each group) and were acclimatized for one week before the actual experiment. The animals were kept in polypropylene cages in an environmentally controlled room with a $12 \mathrm{~h}$ light- $12 \mathrm{~h}$ dark cycle at $24 \pm 2^{0} \mathrm{C}$, and $60 \%( \pm 15)$ relative humidity. Animals were allowed free access to pellet diet (Hindustan Lever Ltd, Bombay, India) and water ad libitum. Guidelines issued by the CPCSEA for the care and uses of laboratory animals were strictly followed. The study had the approval of the animal ethics committee.

\subsection{Plant material and other consumables}

Bergenia ligulata was collected from the Kashmir valley in India, and authenticated by a Taxonomist. All the chemicals and culture media used in this study were of analytical grade and were procured from the standard commercial sources in India. Thiobarbituric acid was procured from Sigma Chem. Co. The control allopathic drug diclofenac sodium (brand name voveran) was obtained from the local pharmacy.

\subsection{Preparation of the aqueous and alcoholic extracts}

Freshly collected rhizomes were chopped, dried, crushed and powdered in a grinder. To prepare the aqueous extract, $10 \mathrm{gm}$ crude powder was mixed well in $50 \mathrm{ml}$ of warm distilled water, and the mixture was left overnight in a conical flask. Following day, the mixture was filtered through muslin cloth, and the aliquot was kept separately in a pre-sterilized glass container and stored in refrigerator. The residue left after the first extraction was subjected to re-extraction in 50 $\mathrm{ml}$ water, and the mixture was kept for another 12 hour. The second aliquot obtained after filtering the mixture through muslin cloth was mixed with the first aliquot and stored. This final aliquot, the aqueous extract was used for testing the antibacterial and antiinflammatory activity. To avoid contamination, the aliquot was stored in refrigerator in autoclaved screw capped vials. Difference in the weight of the crude powder and the weight of the residue left after obtaining the aqueous extract was used to calculate the amount of the crude drug present in the aqueous extract. For preparing a 50\% aqueous-ethanolic extract, Soxhlet apparatus was used. The extract was dried under reduced pressure using a rotatory flash evaporator. This extract was also stored under similar conditions as described for the aqueous extract. The percent yield for the aqueous extract and for the $50 \%$ ethanolic extract, respectively, was $45 \%$ and $50 \%$. The extracts were used within two days of preparation.

\subsection{Experimental protocol}

For evaluating the effect of the aqueous or alcoholic extracts on carrageenan-induced inflammation model in rats, the animals were divided into different groups. Group-I rats (Normal Control, NC) received normal saline and group-II (Carrageenan, C) rats were injected with carrageenan in their hind paw, as described below, to induce inflammation. Group-III (Carrageenan + Aqueous extract, $\mathrm{C}+\mathrm{Aq}$ ) and group-IV rats (Carrageenan $+50 \%$ ethanolic extract, $\mathrm{C}+\mathrm{E}-\mathrm{A})$, respectively, were treated with the aqueous extract and $50 \%$ ethanolic extract of B. ligulata at a dose corresponding to $1 \mathrm{~g} / \mathrm{kg}$ body weight, p.o. In group-V (Carrageenan + Diclofenac, $\mathrm{C}+\mathrm{D}$ ), diclofenac was administered as an allopathic control to compare the efficacy of the herbal 
extract under investigation. Diclofenac was administered orally at a dose level of $5 \mathrm{mg} / \mathrm{kg} \mathrm{bw}$. In groups III to $\mathrm{V}$, the test compound/ control were administered one hour before injecting carrageenan.

\subsection{Pharmacological evaluation of the anti- inflammatory activity}

Antiinflammatory activity of $B$. ligulata was determined according to the method described by Winter and colleagues [7]. Briefly, $0.1 \mathrm{ml}$ of $1 \%$ carrageenan solution, prepared by suspending 100 $\mathrm{mg}$ carrageenan in $10 \mathrm{ml}$ normal saline solution, was injected into the left hind paw of rat. The swelling (oedema) produced by carrageenan injection was measured by measuring the increase in paw volume every hour for three hours using a plathysmometer (Ugo Basile, Italy). The percent inhibition was calculated as follows: $\mathrm{Vc}-\mathrm{Vt} / \mathrm{Vc}$ $\mathrm{x} 100$, where $\mathrm{Vc}$ is the volume of edema measured in the hind paw, and $\mathrm{Vt}$ is the volume of edema in the drug treated group. Volume of edema was derived by taking the difference in the volume of left hind paw receiving carrageenan injection minus the volume of right hind paw, which was not injected with carrageenan.

\subsection{Biochemical analysis}

The biochemical estimations were carried out from the tissue samples obtained from the drug treated and control groups. Biological samples were processed as described earlier [8]. Following biochemical estimations were made from the hepatic tissue samples: succinate dehydrogenase [9], superoxidase dismutase [10], xanthine oxidase [11], lipid peroxidation [12], and glutathione [13]. For biochemical analysis, animals were sacrificed four hours after administering carrageenan. All analyses were carried on the fresh samples, and throughout the period of analysis samples were kept at 0 to $4^{\circ} \mathrm{C}$.

\subsection{Antibacterial activity}

The antibacterial activity was tested using the diffusion method [14]. A loop of bacteria from the agar-slant stock was cultured in the nutrient broth overnight and spread with a sterile cotton swap into the Petri plates containing $20 \mathrm{ml}$ of nutrient agar. Wells (9 $\mathrm{mm}$ in diameter) were made in nutrient agar and impregnated with a fixed volume of plant extract $(10 \mathrm{mg} / \mathrm{ml}, 25 \mathrm{mg} / \mathrm{ml}$ or 50 $\mathrm{mg} / \mathrm{ml})$. The culture plates were incubated at $37^{\circ} \mathrm{C}$ for 24 hours. Antibiotic ciprofloxacin $(25 \mu \mathrm{g} / \mathrm{ml}$ or $50 \mu \mathrm{g} / \mathrm{ml}$ ) was used as positive control. Following $24 \mathrm{~h}$ incubation, the diameter in $\mathrm{mm}$ of the inhibitory or clear zones around the well was measured. The zone of inhibition was calculated by measuring the minimum dimension of the zone of no microbial growth around the well.

\subsection{Statistical analysis}

Mean \pm S.D. of all determinations in a group was taken, and the percent increase or decrease in some parameters was also calculated assuming the mean value of the control group as $100 \%$.

\section{Results and Discussion}

Evaluation of the anti-inflammatory activity measuring carrageenan-induced paw edema is one of the widely used pharmacological methods. It measures the ability of a compound to reduce local oedema produced by injecting carrageenan in rat hind paw. The formation of oedema is the result of a synergism between various inflammatory mediators that increase vascular permeability and/or mediators that increase the flow of blood [15]. It is a biphasic event. The early phase is observed around $1 \mathrm{~h}$ after carrageenan injection and is attributed to the release of histamine and serotonin. In the late phase, molecules such as prostaglandins are released [16]. In this study, aqueous and $50 \%$ ethanolic extracts of the rhizomes of Bergenia ligulata are reported to attenuate the inflammatory response as determined by pharmacological and biochemical measurements. The treatment significantly decreased the inflammation as can be seen in figure 1. The activity level of succinate dehydrogenase $(\mathrm{SDH})$, which has been reported to rise in inflammation [17], decreased in rats receiving the extract treatment (Figure 2). SDH is a key inner mitochondrial membrane enzyme linked with the energy yielding citric acid cycle in living cells. An increase in SDH would mean an increased supply of ATP to liver and possibly other tissues including the inflamed tissue. 


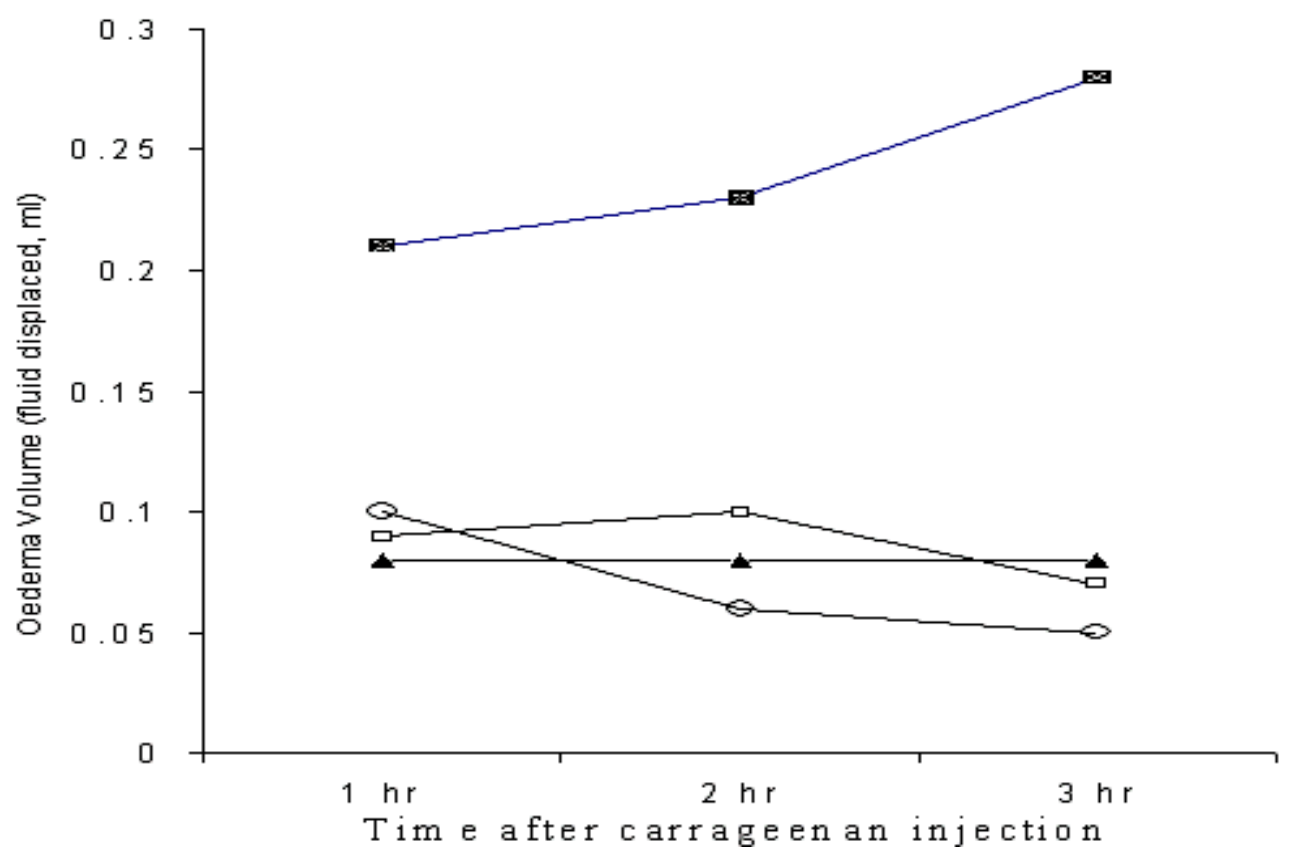

Figure 1: Effect of Bergenia ligulata on carrageenan induced oedema. $\times$ : Paw volume measured following the injection of carrageenan in rat hind paw; $\square$ : Paw volume in rats treated with the aqueous extract in inflammation model; $\Delta$ : Group treated with $50 \%$ ethanolic extract; and o: Rats treated with diclofenac. In all groups, the paw volume was less in comparison to the carrageenan alone treated group.

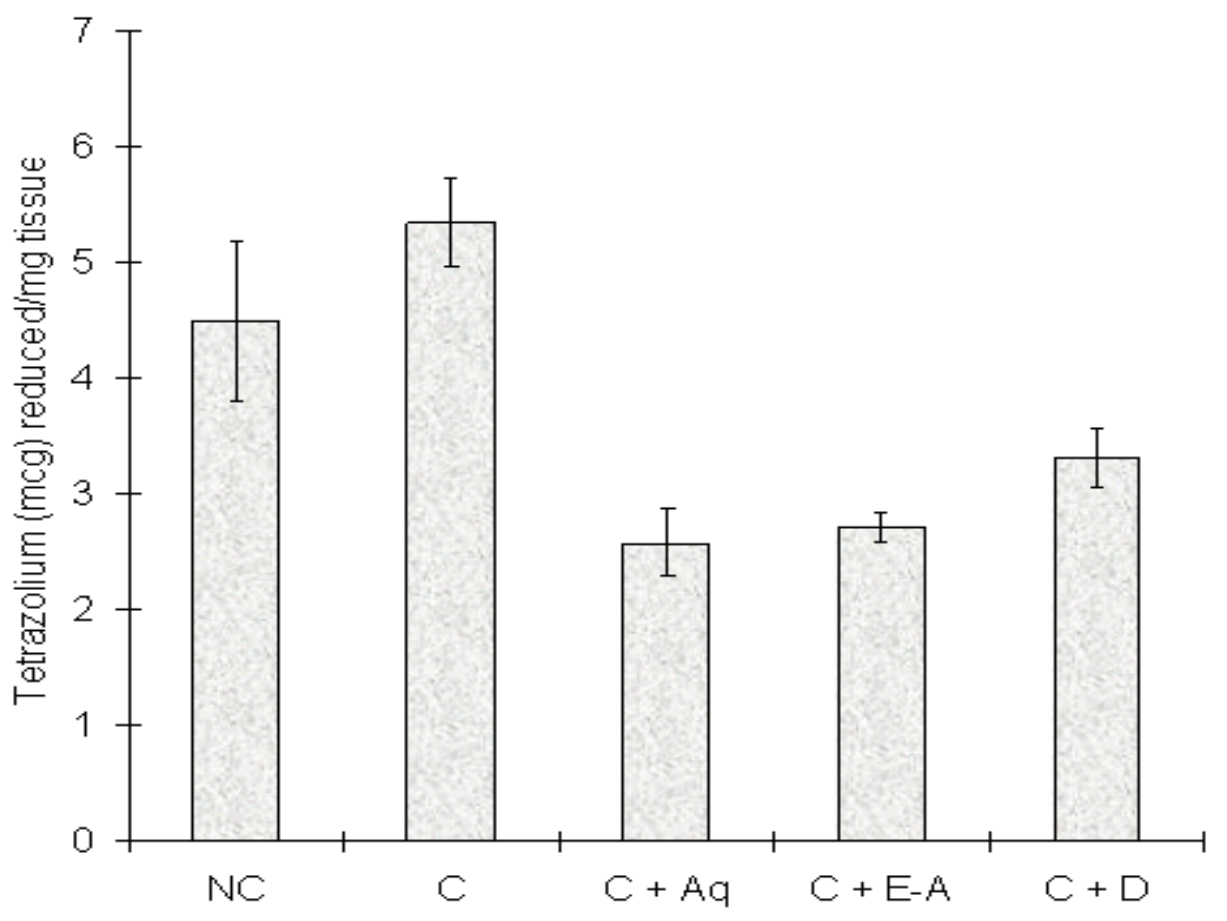

Figure 2: Succinate dehydrogenase in rats treated with Bergenia ligulata for treating inflammation. NC: normal control receiving the vehicle alone, $\mathrm{C}$ : animal group receiving carrageenan injection, $\mathrm{C}+\mathrm{Aq}$ : treated with aqueous extract, $\mathrm{C}+\mathrm{E}-\mathrm{A}$ : treated with $50 \%$ ethanolic extract, and $\mathrm{C}+\mathrm{D}$ : treated with diclofenac. Succinate dehydrogenase has 
been reported to increase in animal model of inflammation. Extract treatment could significantly bring down the increased value.

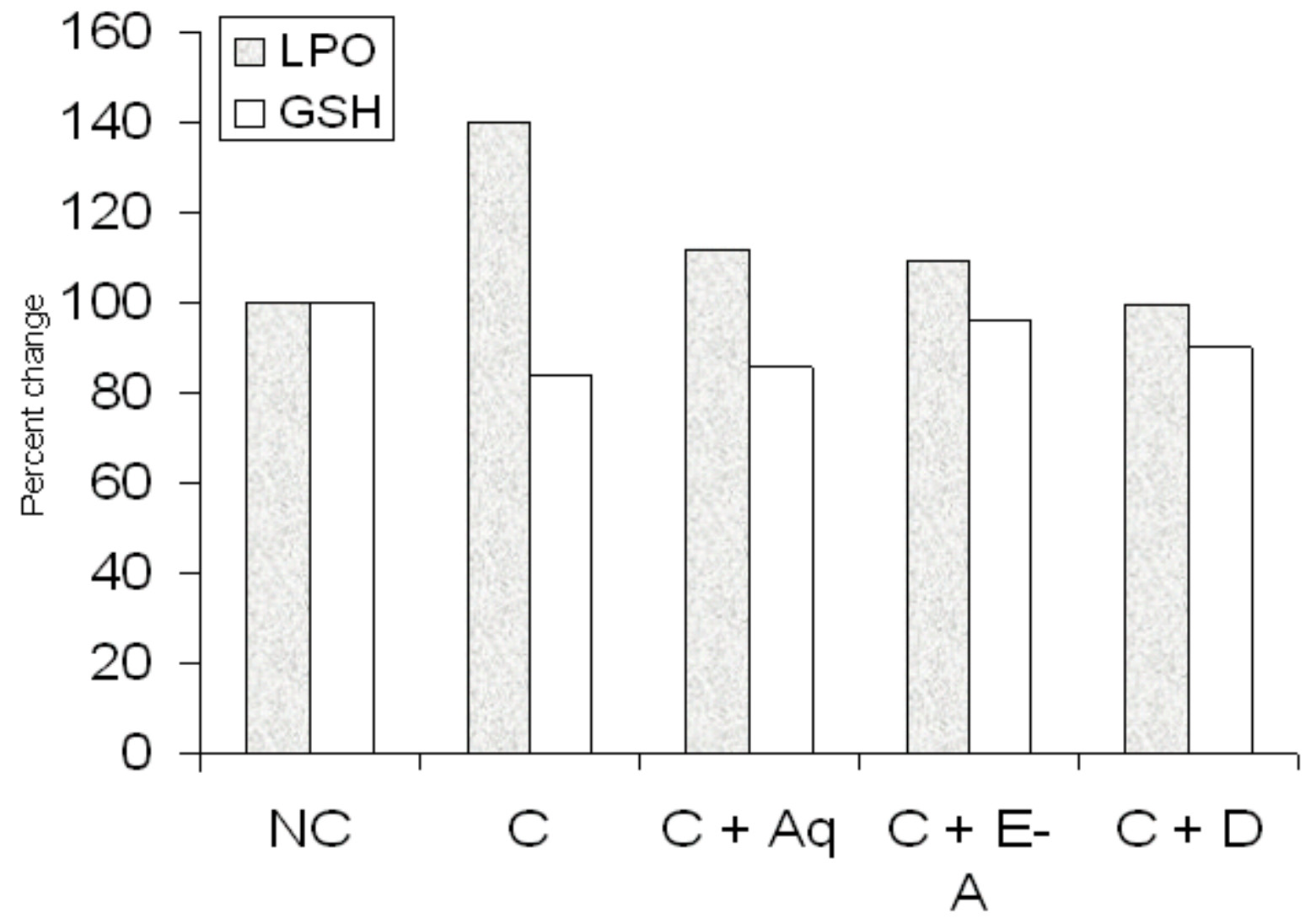

Figure 3: Lipid peroxidation and glutathione in rats following the treatment with B. ligulata in inflammation. NC: normal control receiving the vehicle alone, $\mathrm{C}$ : the group receiving carrageenan injection, $\mathrm{C}+\mathrm{Aq}$ : treated with aqueous extract, C+E-A: treated with 50\% ethanolic extract, and C+D: treated with diclofenac. Following inflammation, lipid peroxidation value shows a marked increase, while glutathione is reduced. Treatment with the extract is clearly shown to reverse the effect on the respective parameters.

The delayed onset of the carrageenan induced oedema has been linked to neutrophil infiltration, the release of neutrophil derived-mediators and free radicals [18]. The role of oxygen-derived free radicals and the oxidants in inflammation has been documented [19] and a large body of evidence is available linking the reactive oxygen species (ROS) to the pathophysiology of tissue damage associated with the inflammatory response. Free radicals cause the peroxidation of membrane lipids, and lead to the depletion of tissue glutathione by various mechanisms. In this study, we observed a significant increase in lipid peroxidation in the group of rats receiving carrageenan injection (Figure 3). Treatment with the extract significantly brought down the increased lipid peroxidation values. In states of oxidative stress, glutathione is depleted leading to further peroxidation of lipid molecules [20]. In carrageenan-injected rats, we observe that the tissue glutathione concentration gets decreased. However, in rats receiving the $50 \%$ ethanolic extract, glutathione concentration was almost similar to the control rats (Figure 3). It is interesting to note that only the alcoholic extract was shown to increase the level of glutathione in comparison to the aqueous extract that exhibited little or no effect on glutathione concentration. A possible explanation for this could be attributed to the action of bergenin, a constituent of $B$. ligulata. Bergenin is a $\mathrm{C}$-glucoside of 4-O-methyl gallic acid that has been isolated from the alcoholic extract of Bergenia and other plant species [21], and is well known for its therapeutic effects on the gastrointestinal diseases and antiinflammatory effects. Studies have reported that bergenin, over a 
concentration range from 1 to $300 \mu \mathrm{M}$, could recover the decreased levels of glutathione in a dose dependent manner in hepatocytes [21]. Bergenin has been isolated from the methanolic extract of $B$. ligulata, and therefore, the antiinflammatory activity of the alcoholic extract of B. ligulata seen in this study can be attributed in part to the effect of bergenin. Literature has further suggested that the effects of bergenin can be related to its free radical suppressing activity
[21]. In this study, we also observed the activity of xanthine oxidase (Figure 4), a superoxidegenerating enzyme, and superoxide dismutase (Figure 5), a superoxide-scavenging enzyme in carrageenan as well as extract treated rats. The results suggest that the extract attenuated the activity of the superoxide-generating enzyme (xanthine oxidase) and also enhanced the activity of superoxide scavenger (superoxide dismutase).

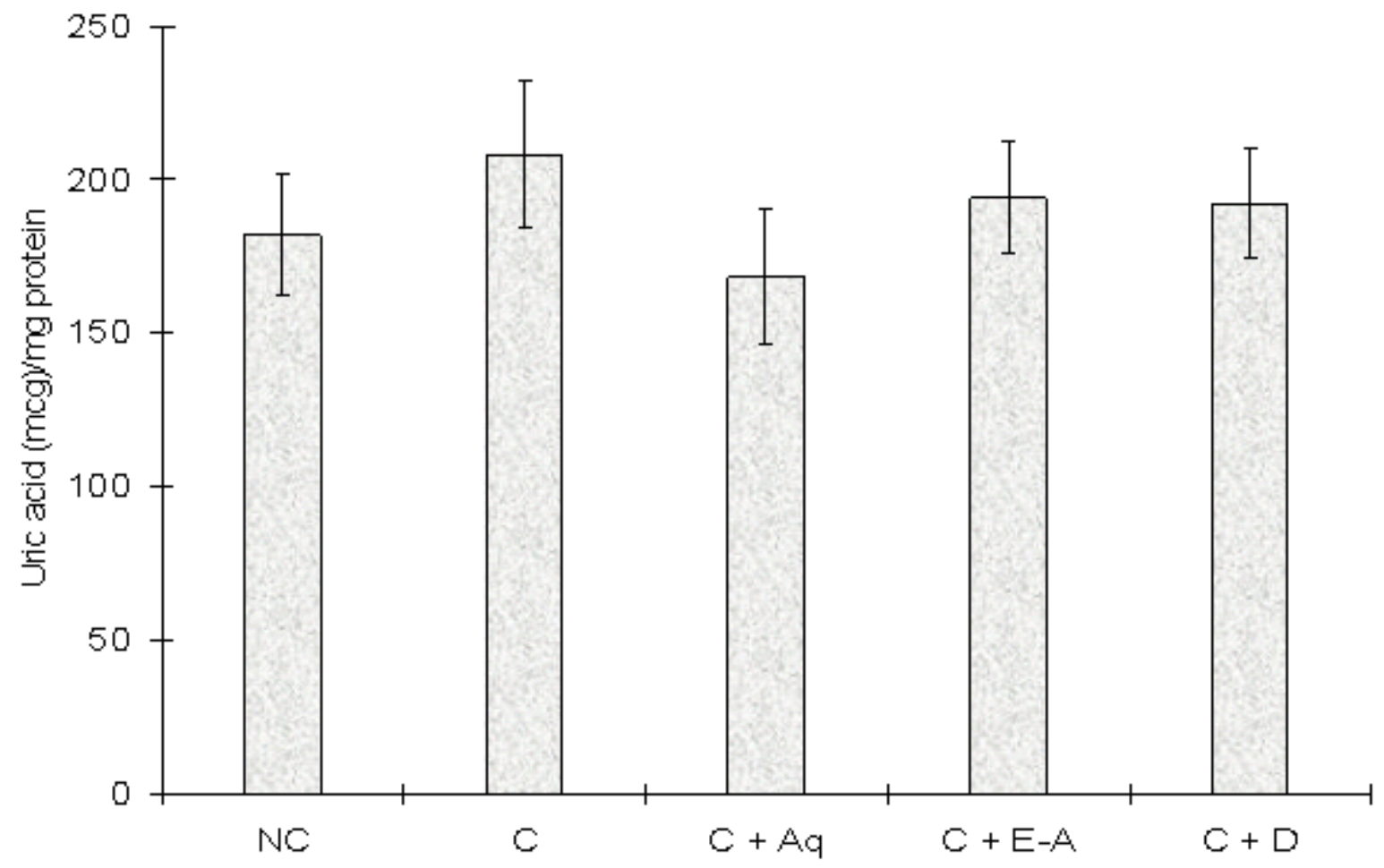

Figure 4: Effect of the treatment of B. ligulata on xanthine oxidase in rat model of inflammation. NC: normal control receiving the vehicle alone, $\mathrm{C}$ : the group receiving carrageenan injection, $\mathrm{C}+\mathrm{Aq}$ : treated with aqueous extract, $\mathrm{C}+\mathrm{E}-\mathrm{A}$ : treated with $50 \%$ ethanolic extract, and $\mathrm{C}+\mathrm{D}$ : treated with diclofenac. Xanthine oxidase is reported to be a pro-oxidant enzyme, causing an increase in the generation of superoxide. Treatment with the $50 \%$ ethanolic extract could alleviate the increased activity of xanthine oxidase.

As shown in Table I, aqueous, $50 \%$ ethanolic and methanolic extracts of $B$. ligulata rhizomes were tested for their ability to inhibit the growth of E. coli, B. subtilis, and $S$. aureus at the dose levels of 10,25 or $50 \mathrm{mg} / \mathrm{ml}$ for each extract. At a dose level of $50 \mathrm{mg} / \mathrm{ml}$, the antibacterial effect was most significant. Incidentally, the antibacterial effect of the extracts at this level was comparable to ciprofloxacin $(25 \mathrm{mcg} / \mathrm{ml})$. The results clearly suggest that $B$. ligulata possesses a strong antibacterial activity.

The antiinflammatory and the antibacterial effects of $B$. ligulata can be attributed to the presence of sterols, glycosides and other chemical constituents present in Bergenia spp. In the roots of $B$. ligulata and $B$. strecheyi, bergenin and $\beta$ sitosterol [4] and recently paashaanolactone (1) have been isolated [22]. Simpler phenolic derivatives such as arbutin, 2-O-galloylarbutin, 6- 
O-galloylarbutin and $p$-galloyloxy- $\beta$-D-glucoside have also been identified in the Bergenia ligulata. The antiinflammatory and the antibacterial activity of $B$. ligulata, as reported in this study, can be attributed, in part, to these and other chemical moieties. An important constituent of the extract, $\beta$-sitosterol (a phytosterol) that has been isolated from Bergenia species and other plant species has been documented for beneficial effects. Approximately $80 \%$ of the total phytosterol content of higher plants is composed of $\beta$ sitosterol [23] that differs from the major animal sterol (cholesterol) only by an extra ethyl group in its side chain. The $\beta$-sitosterol possesses several profound biological effects that also include the antiinflammatory effect [24]. In a study by Bouic [25], $\beta$-sitosterol and its glucoside have been shown to enhance $\mathrm{T}$-cell proliferative responses and the release of IL-2 and $\gamma$-interferon, and enhance the in vitro NK-cell activity. The $\beta$ sitosterol and its glucoside exert their effects on Tcells in hormonal concentration (picograms to femtograms) and therefore can be effective even if their absorption from the gastro-intestinal tract is poor; in humans no more than $5 \%$ of the daily intake is absorbed [26]. Thus, it is concluded that the antiinflammatory and antibacterial effects of B. ligulata can be due to the synergistic effect of pro-inflammatroy enzyme inhibitors, free radical scavengers or because of the corticoid like effects of some ingredients present in the extract. In conclusion, this study reports the antiinflammatory and antibacterial activity of B. ligulata extracts. Besides these activities, the study reports the radical scavenging activity of the rhizomes of $B$. ligulata, and establishes the therapeutic rationale of using B. ligulata in India System of Medicine.

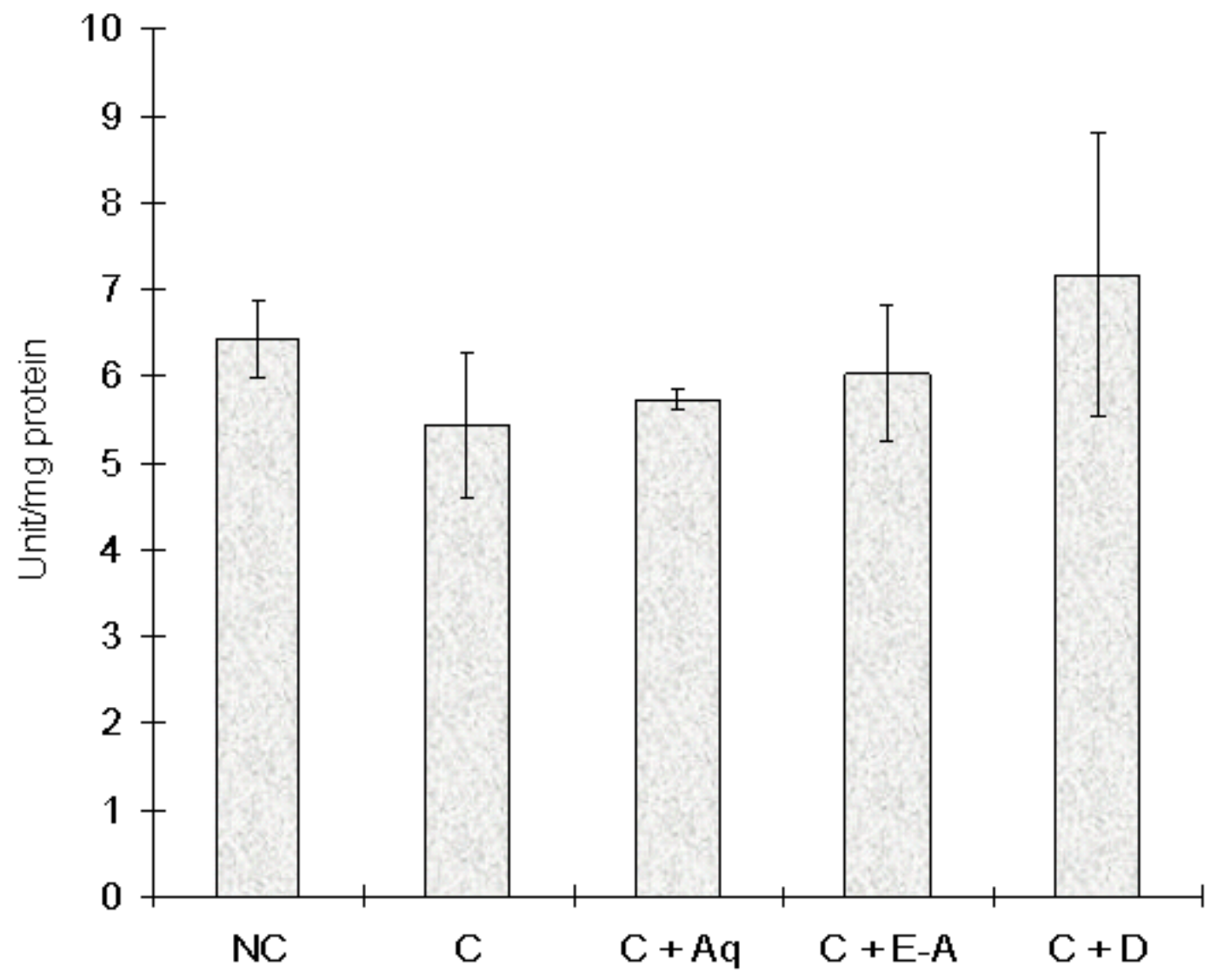

Figure 5: Superoxide dismutase in rats treated with B. ligulata. NC: normal control receiving the vehicle alone, C: the group receiving carrageenan injection, $\mathrm{C}+\mathrm{Aq}$ : treated with aqueous extract, $\mathrm{C}+\mathrm{E}-\mathrm{A}$ : treated with $50 \%$ ethanolic extract, and $\mathrm{C}+\mathrm{D}$ : treated with diclofenac. This enzyme scavenges the superoxide anion radical. In animal model of 
inflammation, superoxide dismutase showed a significant decrease. The enzyme level increased following the treatment with the extract as well as the diclofenac.

\section{Acknowledgments}

Authors acknowledge the Vice Chancellors of $\mathrm{KU}$ and $\mathrm{JH}$ for their interest and encouragement, and UGC for partial financial support for this work.

\section{References}

1. Asolkar LV, Kakkar KK, Chakre OJ. Glossary of Indian medicinal plants with active principles. New Delhi: Publication and Information Directorate, CSIR 1992: 122.

2. Garimella TS, Jolly CI, Narayanan S. In vitro studies on antilithiatic activity of seeds of Dolichos biflorus Linn and rhizomes of Bergenia ligulata Wall. Phytotherapy Research 2001; 15: 351-355.

3. Rajbhandari $M$, Wegner U, Schopke T, Lindequist $\mathrm{U}$, Mentel R. Inhibitory effect of Bergenia ligulata on influenza virus A. Pharmazie 2003; 58: 268-271.

4. Bahl CP, Murari R, Parthasarathy MR, Seshadri TR. Indian Journal of Chemistry 1974; 12: 1038-1039.

5. Umashankar DC, Amric SC, Deepak M, Rakesh M, Sukhdev SH. Paashaanolactone from Bergenia ligulata. Phytochemistry 1998; 47: 907-909.

6. Ali S, and Mann DA. Signal transduction via the NF-kappaB pathway: a targeted treatment modality for infection, inflammation and repair. Cell Biochemistry and Function 2004; 22: 67-79.

7. Winter CA, Ristey EA, and Nuss GW. Carrageenan induced edema in hind paw of the rat as an assay for antiinflammatory drugs. Proceeding of Society of Experimental Biology Medicine 1962; 111: 544-552.

8. Ali S, Diwakar G, Pawa S, Siddiqi MR, Abdin M.Z Ahmad FJ, Jain SK. Xanthine oxidasederived reactive oxygen metabolites contribute to liver necrosis: protection by 4hydroxypyrazolo [3,4-d]pyrimidine. Biochimica et Biophysica Acta 2001; 1536: 21-30.

9. Kun E, Abood LG. Colermetric estimation of succinic dehydrogenase by triphenyle chloride. Science 1949; 109: 144-146.

10. Marklund S, Marklund G. Involvement of the superoxide anion radical in the autoxidation of pyrogallol and a convenient assay for superoxide dismutase. Europian Journal of Biochemistry 1974; 47: 469-474.

11. Stirpe F, Della Corta E. The regulation of rat liver xanthine oxidase, conversion in vitro of the enzyme activity from dehydrogase (type D) to oxidase (type O). Journal of Biological Chemistry 1969; 244: 3855-3863.

12. Wright JR, Colby HD, Miles PR. Cytosolic factors which affect microsomal lipid peroxidation in lung and liver. Archives of Biochemistry and Biophysics 1981; 206: 296304.

13. Jollow DJ, Mitchell JR, Zampaglione N, and Gillette JR. Bromobenzene-induced liver necrosis. Protective role of glutathione and evidence for 3,4-bromobenzene oxide as the hepatotoxic metabolite. Pharmacology 1974; 11: 151-69.

14. Pelczar MJ, Chan ECS, and Krieg NR. Microbiology. New York: Mc Graw Hill; 1993: 578.

15. Ialenti A, Ianaro A, Moncada S, Di Rosa M. Modulation of acute inflammation by endogenus nitric oxide. European Journal of Pharmacology 1995; 211: 177-182.

16. Crunkhon P, Meacock SER. Mediators of the inflammation induced in the rat paw by carrageenan. British Journal of Pharmacology 1971; 42: 392-402.

17. Naik SR, Kalyanpur SN, Sheth UK. Effect of antiinflammatory drugs on glutithione levels and liver succinic dehydrogenase activity in carrageenan edema and cotton pellet granuloma in rat. Biochemical Pharmacology 1972; 21: 511-516. 
18. Cuzzocrea S, Costantino G, Mazzon E, Zingarelli B, De Sarro A, Caputi AP. Protective effect of $\mathrm{Mn}$ (III) tetrakis (4-benzoic acid) porphyrin (MnTBAP), a superoxide dismutase mimetic, in paw oedema induced by carrageenan in the rat. Biochemical Pharmacology 1999; 58: 171-176.

19. Salvemini D, Wang ZQ, Bourdon DM, Stern MK, Currie MG, Manning PT. Evidence of peroxynitrite involvment in the carrageenaninduced rat paw oedema. European Journal of Pharmacology 1996; 303: 217-220.

20. Pandey S, Sharma M, Chaturvedi P, Tripathi YB. Protective effect of Rubia cordifolia on lipid peroxide formation in isolated rat liver homogenate. Indian Journal of Experimental Biology 1994; 32: 180-183.

21. Kim HS, Lim HK, Chung MW, Kim YC. Antihepatoxic activity of bergenin, the major constituent of Mallotus jponicus, on carbon tetrachloride-intoxicated hepatocytes. Journal of Ethanopharmacology 2000; 69: 79 - 83.

22. Chandrareddy UD, Chawla AS, Mundkinajeddu D, Maurya R, Handa SS.
Paashanolactone from Bergenia ligulata. Phytochemistry 1998; 47: 907-909.

23. Akihisa T, Kokke WCRC, Tamura J. Natural occurring sterols and related compounds from plants. In: Physiology and Biochemistry of Sterols. Patterson GW, Nes WD, editors. Champaign: American Oil Chemist Society; 1991: 172-223.

24. Yamamoto M, Matsui T, Sugiyama K, Yakota M, Nakagomi K, Nakazawa $H$. Antiinflammatory active constituents of Aloe arborescents Miller. Agricultural and Biological Chemistry 1991; 55: 1627-1629.

25. Bouic PJD, Etsebeth S, Liebenberg RW, Albrecht CF, Pegel K, van Jaarsveld PP. Betasitosterol and Beta-sitosterol glucoside stimulate humen peripheral blood lymphocyte proliferation: Implication for their use as an immmunomodulatory vitamin combination. International Journal of Immunopharmacolgy 1996; 18: 693-700.

26. Salen G, Ahrens EH, Grundy SM. Metabolism of $\beta$-sitosterol in man. Journal of Clinical Investigation 1970; 49: 952-967. 